\title{
Multidecadal variability in surface albedo feedback across CMIP5 models
}

\author{
Adam Schneider ${ }^{1}$, Mark Flanner ${ }^{1}$, Justin Perket ${ }^{2}$ \\ ${ }^{1}$ Department of Climate and Space Sciences and Engineering, University of Michigan, Ann Arbor, MI \\ ${ }^{2}$ National Center for Atmospheric Research, Boulder, CO
}

\section{Key Points:}

- Periods with global warming of at least $0.5 \mathrm{~K}$ provide reasonable estimates of surface albedo feedback

- Models' 21st century surface albedo feedbacks are strongly correlated with their mean decadal-scale feedbacks

- 16 CMIP5 models show significant strengthening in decadal-scale surface albedo feedback throughout the 21 st century

This is the author manuscript accepted for publication and has undergone full peer review but has not been through the copyediting, typesetting, pagination and proofreading process, which may lead to differences between this version and the Version of Record. Please cite this article as doi: 10.1002/2017GL076293

Corresponding author: Adam Schneider, amschne@umich.edu

This article is protected by copyright. All rights reserved. 


\begin{abstract}
Previous studies quantify surface albedo feedback (SAF) in climate change, but few assess its variability on decadal timescales. Using the Coupled Model Intercomparison Project Version 5 (CMIP5) multi-model ensemble dataset, we calculate time evolving SAF in multiple decades from surface albedo and temperature linear regressions. Results are meaningful when temperature change exceeds $0.5 \mathrm{~K}$. Decadal scale SAF is strongly correlated with century scale SAF during the 21st century. Throughout the 21st century, multi-model ensemble mean SAF increases from 0.37 to $0.42 \mathrm{Wm}^{-2} \mathrm{~K}^{-1}$. These results suggest models' mean decadal scale SAFs are good estimates of their century scale SAFs if there is at least $0.5 \mathrm{~K}$ temperature change. Persistent SAF into the late 21 st century indicates ongoing capacity for Arctic albedo decline despite there being less sea-ice. If the CMIP5 multimodel ensemble results are representative of the Earth, we cannot expect decreasing Arctic sea-ice extent to suppress SAF in the 21st century.
\end{abstract}

\title{
1 Introduction
}

Radiative transfer is the primary phenomenon governing energy exchange between Earth and the surrounding vacuum. Therefore, Earth's total energy budget is well approximated by the difference in absorbed solar and emitted terrestrial radiation at the top of the atmosphere (TOA). Simple energy balance models use the TOA approximation to demonstrate enhanced climate sensitivity from surface albedo feedbacks. Budyko [1969] and Sellers [1969], for example, find that relatively small changes in incident solar radiation coupled with changes in planetary albedo can cause glaciation or deglaciation of the planet in climate models, identifying snow and ice albedo feedback as a possible mechanism for instability in the climate state. The snow and ice albedo feedback is a positive feedback that accelerates climate change when increasing (decreasing) temperature causes snow and ice cover to decrease (increase), reducing (enhancing) albedo and further enhancing surface warming (cooling). Because snow and ice are often much brighter than their underlying surfaces, the high albedo contrast potentiates snow and ice albedo feedbacks to amplify Arctic climate change where increasing temperatures reduce surface albedo and accelerate melt. Qu and Hall [2014] examine Northern Hemisphere snow albedo feedback in Coupled Model Intercomparison Project Version 5 (CMIP5) models and show a strong correlation between feedback in the spring time melting season and feedback in climate change. This correlation suggests the seasonal cycle Northern Hemisphere snow albedo feedback derived from remote sensing observations can constrain the climate change feedback in models. Crook and Forster [2014], however, find discrepancies between Northern Hemisphere surface albedo feedback (SAF) in the climate change and seasonal cycle contexts when comparing observations to models. These results cast doubt on the predictive capability of the seasonal cycle SAF as it relates to the climate change feedback. Constraining SAF in climate models is important for improving the accuracy of climate change predictions from intercomparison projects cited frequently by the Intergovernmental Panel of Climate Change (IPCC) reports. The IPCC fifth assessment report [Intergovernmental Panel on Climate Change, 2014; Flato et al., 2014], for example, cites numerous studies showing drastic reductions in summer Arctic sea ice extent by 2100 in CMIP5 models. This reduction in Arctic sea-ice impacts Earth's total energy budget and amplifies climate change via the SAF.

Pistone et al. [2014] and Cao et al. [2015], for example, relate the recent decline in observed planetary albedo directly to the loss of Arctic sea-ice cover. Rapid Arctic sea-ice loss and rising surface temperatures are characteristic of transient future climate simulations under the $8.5 \mathrm{Wm}^{-2}$ greenhouse gas radiative forcing Representative Concentration Pathway (RCP8.5). Hall [2004] demonstrates in a coupled atmosphere-ocean model simulation that SAF enhances both polar amplification of surface temperature anomalies and surface temperature at all latitudes in the equilibrium response to $\mathrm{CO}_{2}$ doubling. Winton [2006a] and Pithan and Mauritsen [2014] find SAF to be a secondary driver of po- 
lar amplification, however, citing temperature feedbacks as the primary contributor. In a consistent evaluation of global climate feedbacks in coupled atmosphere-ocean climate models, Soden and Held [2006] find SAF the third strongest positive feedback in current climate after water vapor and cloud feedbacks. Winton [2006b] reports a multi-mean SAF of $0.3 \mathrm{Wm}^{-2} \mathrm{~K}^{-1}$ in the IPCC fourth assessment climate models. Other studies quantify snow and SAF in global climate models [Qu and Hall, 2006, 2007; Fletcher et al., 2012; Vial et al., 2013; Crook and Forster, 2014; Qu and Hall, 2014; Andry et al., 2017] and from remote sensing observations [Hall and Qu, 2006; Fernandes et al., 2009; Flanner et al., 2011; Hudson, 2011; Fletcher et al., 2012; Qu and Hall, 2014; Fletcher et al., 2015]. Andry et al. [2017] examine time dependent variations in SAF in six CMIP5 models using a moving window technique. Here, we use a similar technique to expand on previous analyses in 36 CMIP5 models to address the following.

As Arctic sea-ice continues to melt, we expect SAF to weaken as less highly reflective snow and ice remains to allow large changes in albedo. The onset of 21st century SAF weakening is unclear, however, as nearly all previous studies do not resolve the timedependency of SAF. In calculating climate change SAF on multiple decadal timescales, we evaluate its temporal evolution and identify when and if weakening occurs. Allowing SAF to vary on decadal time scales also allows for testing its predicative capability of models' longer, century-scale feedback. In comparing multiple models' decadal timescale feedbacks to their century-scale feedbacks, we can also evaluate how well remote sensing products, limited in duration by the satellite era, may be able to constrain longer timescale climate change SAF. In this paper, we present a new technique for calculating time evolving SAF in 36 CMIP5 models in transient historical and future climate simulations ranging from 1850-2300. Contrary to our initial expectations, we discover small but significant strengthening of SAF throughout the 21st century in most CMIP5 climate models.

\section{Methods and Data}

SAF is defined as the change in global mean net TOA shortwave irradiance caused by the change in surface albedo per global mean surface temperature change. It can be expressed mathematically in the following form [Hall, 2004; Winton, 2006b; Colman, 2013; Crook and Forster, 2014],

$$
\mathrm{SAF}=\frac{\partial Q_{n e t}}{\partial \alpha_{S}} \frac{\Delta \alpha_{S}}{\Delta T_{S}}
$$

where $\partial Q_{n e t} / \partial \alpha_{S}$ is the radiative kernel and $\Delta \alpha_{S}$ and $\Delta T_{S}$ are surface albedo and surface temperature changes, respectively. Global mean temperature change is used in this study instead of hemispheric or zonal means enabling direct comparisons to other climate feedbacks.

SAF is calculated over separate $11,23,47$, and 94-year time periods within the CMIP5 multi-model ensemble simulations in transient historical and future climate under the RCP8.5. These time periods are selected to maximize the number of samples within the 21 st century for decadal, quarter century, half century, and full century scale SAF between 2006 and 2099. The CMIP5 multi-model ensemble dataset contains monthly mean surface upwelling and downwelling irradiance used to calculate grid-cell albedo and annual global mean surface temperature [Taylor et al., 2012]. Monthly grid-cell albedo and annual global mean temperature are used to compute 11, 23, 47, and 94-year changes in grid-cell albedo by month and global mean temperature using least squares regressions.

Because least squares regressions are particularly sensitive to outliers, yearly gridcell albedo by month and global mean temperature time series are first run forwards and backwards through a low-pass Butterworth filter using the convolution theorem. The lowpass Butterworth filter is defined by the power gain in terms of its transfer function [Roberts 
and Roberts, 1978],

$$
\left|H_{B}(j \omega)\right|^{2}=\left[1+\frac{\tan (\omega T / 2)}{\tan \left(\omega_{c} T / 2\right)}\right]^{-2 n} .
$$

The discrete transfer function $H_{B}$ gives the complex frequency domain response and is specified by the sampling interval $T$, corner-frequency $\omega_{c}$, and order of the filter $n$. With $T=1$ year, $n=1$ and $\omega_{c}=1 / 11$ years $^{-1}$ are selected to damp high frequency signals associated with dynamical modes in the climate system. The El Nino / La Nina Southern Oscillation, for example, can cause short term fluctuations in both albedo and temperature output that obscure long term trends and needlessly affect least squares regressions. After filtering, least squares regressions are computed on filtered grid-cell albedo by month and global mean temperature time series to give the 11, 23, 47, and 94-year changes.

Grid-cell albedo changes for each month are then multiplied by two monthly resolved radiative kernels to give the TOA change in net irradiance caused by the albedo change. This method is introduced by Shell et al. [2008] and Soden et al. [2008] and enables the quantification of SAF in transient climate for a fixed cloud field. Using a fixed cloud field invariant in time is useful here as it allows for direct comparisons of SAF across models independent of their transient atmospheric conditions and cloud feedbacks. The two radiative kernels used in this study are calculated from the Geophysical Fluid Dynamics Laboratory (GFDL) Atmosphere Model (AM2) [Soden et al., 2008] and the Community Earth System Model (CESM1) Community Atmosphere Model (CAM5).

Finally, annual global means are calculated from the 11, 23, 47, and 94-year changes in grid-cell TOA net irradiance. These changes are divided by the respective 11, 23, 47, and 94-year changes in global mean temperature. The resulting quotients give the 11, 23, 47, and 94-year global mean SAF as defined in equation 1. SAF is calculated in this manner for the 36 models listed in Table 1 using the CMIP5 multi-model ensemble output.

\section{Results and Discussion}

Equation 1 shows there is no limit to SAF as the change in global mean surface temperature approaches zero. Figure 1 demonstrates the consequences of this limitless behavior in the calculation of SAF. We scatter SAF against the change in global mean surface temperature in 11,23, 47, and 94-year windows across all historical and future simulations from models listed in Table 1 using both the CAM5 and AM2 radiative kernels. SAF is noisy when temperature change is less than roughly $0.5 \mathrm{~K}$. This temperature change threshold exists for all window lengths, suggesting that at least $0.5 \mathrm{~K}$ warming (or cooling) is necessary to calculate meaningful SAF in climate change. We hereafter use the $0.5 \mathrm{~K}$ temperature change threshold as a cutoff to remove noisy SAF calculations and restrict the following analysis to only meaningful SAF in climate change. Use of different radiative kernels generally results in different scaling of the global SAF but does not result in significant relative changes between different models. Because the primary focus of this study is on the temporal variability of SAF across the CMIP5 models, we hereafter present results using primarily the CAM5 radiative kernel. Narrowing the remaining analysis to just one kernel minimally impacts our main findings while also reducing the study's dimensionality. Furthermore, because the following results are mostly independent of window length, we present our findings from only 23-year and 94-year calculations.

Similar to the considerable spread in the strength of snow albedo feedback reported by $Q u$ and Hall [2014], the strength of SAF in the CMIP5 models is also highly variable, ranging from 0.1 to $0.8 \mathrm{Wm}^{-2} \mathrm{~K}^{-1}$. Figure 2 shows the decadal-scale (23-year) temporal evolution of model- and multi-model mean (black) SAF using the CAM5 radiative kernel spanning three centuries. The temporal evolution of the multi-model mean decadal-scale SAF is dynamic, beginning above 0.7 in historical simulations, settling around 0.4 in the 
CMIP5 21st century- and decadal- scale SAF $\left(\mathrm{Wm}^{-2} \mathrm{~K}^{-1}\right)$

\begin{tabular}{|c|c|c|c|c|c|}
\hline Institute ID & Model Name & 2006-2099 & $2006-2028$ & $2075-2097$ & 23-yr. STD \\
\hline CSIRO-BOM & ACCESS 1.0 & 0.39 & 0.51 & 0.44 & 0.07 \\
\hline CSIRO-BOM & ACCESS1.3 & 0.36 & 0.14 & 0.44 & 0.13 \\
\hline $\mathrm{BCC}$ & BCC-CSM1.1 & 0.40 & - & 0.51 & 0.11 \\
\hline $\mathrm{BCC}$ & BCC-CSM1.1(m) & 0.29 & 0.27 & 0.48 & 0.12 \\
\hline GCESS & BNU-ESM & 0.61 & 0.60 & 0.48 & 0.09 \\
\hline CCCMA & CanCM4* & - & - & - & - \\
\hline CCCMA & CanESM2 & 0.36 & 0.35 & 0.40 & 0.02 \\
\hline NCAR & CCSM4 & 0.47 & 0.38 & 0.49 & 0.05 \\
\hline NCAR & SP-CCSM4 & 0.45 & 0.35 & 0.45 & 0.07 \\
\hline NSF-DOE-NCAR & CESM1(BGC) & 0.47 & 0.43 & 0.49 & 0.03 \\
\hline NSF-DOE-NCAR & CESM1(CAM5) & 0.45 & 0.47 & 0.40 & 0.05 \\
\hline NSF-DOE-NCAR & CESM1(WACCM) & 0.43 & 0.37 & 0.48 & 0.06 \\
\hline CMCC & CMCC-CESM & 0.34 & 0.26 & 0.52 & 0.13 \\
\hline CMCC & CMCC-CM & 0.41 & 0.40 & 0.43 & 0.10 \\
\hline CMCC & CMCC-CMS & 0.41 & 0.50 & 0.43 & 0.06 \\
\hline CNRM-CERFACS & CNRM-CM5 & 0.50 & 0.60 & 0.43 & 0.07 \\
\hline CSIRO-QCCCE & CSIRO-Mk3.6.0 & 0.29 & 0.21 & 0.38 & 0.08 \\
\hline LASG-CESS & FGOALS-g2 & 0.46 & 0.40 & 0.58 & 0.15 \\
\hline NOAA GFDL & GFDL-CM3 & 0.44 & 0.30 & 0.50 & 0.11 \\
\hline NOAA GFDL & GFDL-ESM2G & 0.31 & - & 0.30 & 0.15 \\
\hline NOAA GFDL & GFDL-ESM2M & 0.30 & - & 0.35 & 0.13 \\
\hline NASA GISS & GISS-E2-H & 0.31 & 0.30 & 0.28 & 0.03 \\
\hline NASA GISS & GISS-E2-R & 0.23 & - & 0.24 & 0.04 \\
\hline INM & INM-CM4 & 0.45 & - & 0.42 & 0.12 \\
\hline IPSL & IPSL-CM5A-LR & 0.25 & 0.21 & 0.19 & 0.04 \\
\hline IPSL & IPSL-CM5A-MR & 0.19 & 0.16 & 0.17 & 0.07 \\
\hline IPSL & IPSL-CM5B-LR & 0.23 & 0.13 & 0.14 & 0.07 \\
\hline MIROC & MIROC-ESM & 0.62 & 0.71 & 0.45 & 0.14 \\
\hline MIROC & MIROC-ESM-CHEM & 0.62 & 0.79 & 0.52 & 0.11 \\
\hline MIROC & MIROC4h* & - & - & - & - \\
\hline MIROC & MIROC5 & 0.47 & 0.31 & 0.62 & 0.13 \\
\hline MPI-M & MPI-ESM-LR & 0.36 & 0.21 & 0.35 & 0.09 \\
\hline MPI-M & MPI-ESM-MR & 0.39 & 0.41 & 0.48 & 0.09 \\
\hline MRI & MRI-CGCM3 & 0.44 & 0.24 & 0.58 & 0.15 \\
\hline NCC & NorESM1-M & 0.39 & 0.40 & 0.53 & 0.11 \\
\hline NCC & NorESM1-ME & 0.43 & 0.17 & 0.36 & 0.12 \\
\hline Multi-model mea & & $0.40(0.10)$ & $0.37(0.17)$ & $0.42(0.12)$ & 0.09 \\
\hline
\end{tabular}

Table 1. Model-mean century-scale SAF from 2006-2099 and decadal-scale SAF from 2006-2028 and 2075-2097 using the CAM5 all-sky kernel. The final column shows models' internal variability in 21st century SAF via their standard deviation of 21st century mean 23-year SAF. Bold font highlights models showing significant SAF increases from 2006-2028 to 2075-2097. Asterisks denote models with historical data (included in Figure 1) but without 21st century data. Other "-" denote models that have no simulations with more than $0.5 \mathrm{~K}$ temperature change over the respective time period.

This article is protected by copyright. All rights reserved. 



Figure 1. Surface albedo feedback (SAF) vs. change in global mean surface temperature $\left(\Delta \overline{T_{S}}\right)$. SAF and $\Delta \overline{T_{S}}$ are derived from the CMIP5 multi-model ensemble of simulations across 11, 23, 47, and 94-year windows (by column) within historical and RCP8.5 experiments. Results are displayed for two all-sky radiative kernels (by row). Different colors represent different models and conform to those assigned by the key in Figure 2. Black lines bound data selected for further analysis $\left(\Delta \overline{T_{s}}>0.5 \mathrm{~K} \& \mathrm{SAF}>0 \mathrm{Wm}^{-2} \mathrm{~K}^{-1}\right)$.

21 st century, and finally decreasing to below $0.1 \mathrm{Wm}^{-2} \mathrm{~K}^{-1}$ after 2200 . In the 21 st century, multi-model mean SAF increases from 0.37 to $0.42 \mathrm{Wm}^{-2} \mathrm{~K}^{-1}$. Using the AM2 radiative kernel yields lower values, where 21 st century SAF increases from 0.27 to 0.33 $\mathrm{Wm}^{-2} \mathrm{~K}^{-1}$. SAF calculated from the CAM5 kernel is generally higher than when calculated from the AM2 kernel. This is likely due to improved cloud properties in the CAM5 resulting in reduced cloud masking over the Arctic [Kay et al., 2012]. Century-scale SAF calculated from the AM2 kernel in the 21st century is nearly identical to estimates reported by Vial et al. [2013] $\left(0.3 \mathrm{Wm}^{-2} \mathrm{~K}^{-1}\right)$ in four times $\mathrm{CO}_{2}$ experiments. Results from historical simulations are few after applying the $0.5 \mathrm{~K}$ temperature change cutoff, while simulations extending beyond 2100 are fewer altogether in the CMIP5 multi-model ensemble dataset. In these extended simulations, multi-model mean SAF decreases monotonically after 2150 , decreasing from just under 0.4 to below $0.1 \mathrm{Wm}^{-2} \mathrm{~K}^{-1}$ by 2250 .

The relatively large multi-model variability obscures the small but statistically significant ( $p$-value $=0.04$ ) increase in 21st century model-mean decadal-scale SAF. Using the 2006-2028 and 2075-2097 values from Table 1, where we show each model's mean early and late 21 st-century decadal-scale SAF, respectively, we apply a paired difference test to determine the significance of this apparent increase. The results reveal a statistically significant increase in the models' mean 21st century decadal-scale SAF of $0.07 \mathrm{Wm}^{-2} \mathrm{~K}^{-1}$, about the same as the $0.06 \mathrm{Wm}^{-2} \mathrm{~K}^{-1}$ increase in the multi-model mean SAF over the same period. Because of the relatively large statistical uncertainty $\left(+/-0.06 \mathrm{Wm}^{-2} \mathrm{~K}^{-1}\right.$; $95 \%$ C.I.), however, we must only interpret these results as positive but small change and most likely not negative change in 21 st century SAF.

Finally, we regress each model's 21st century (94-year) ensemble-mean SAF, shown in Table 1 (2006-2099) against its corresponding 21st-century mean decadal-scale (23- 

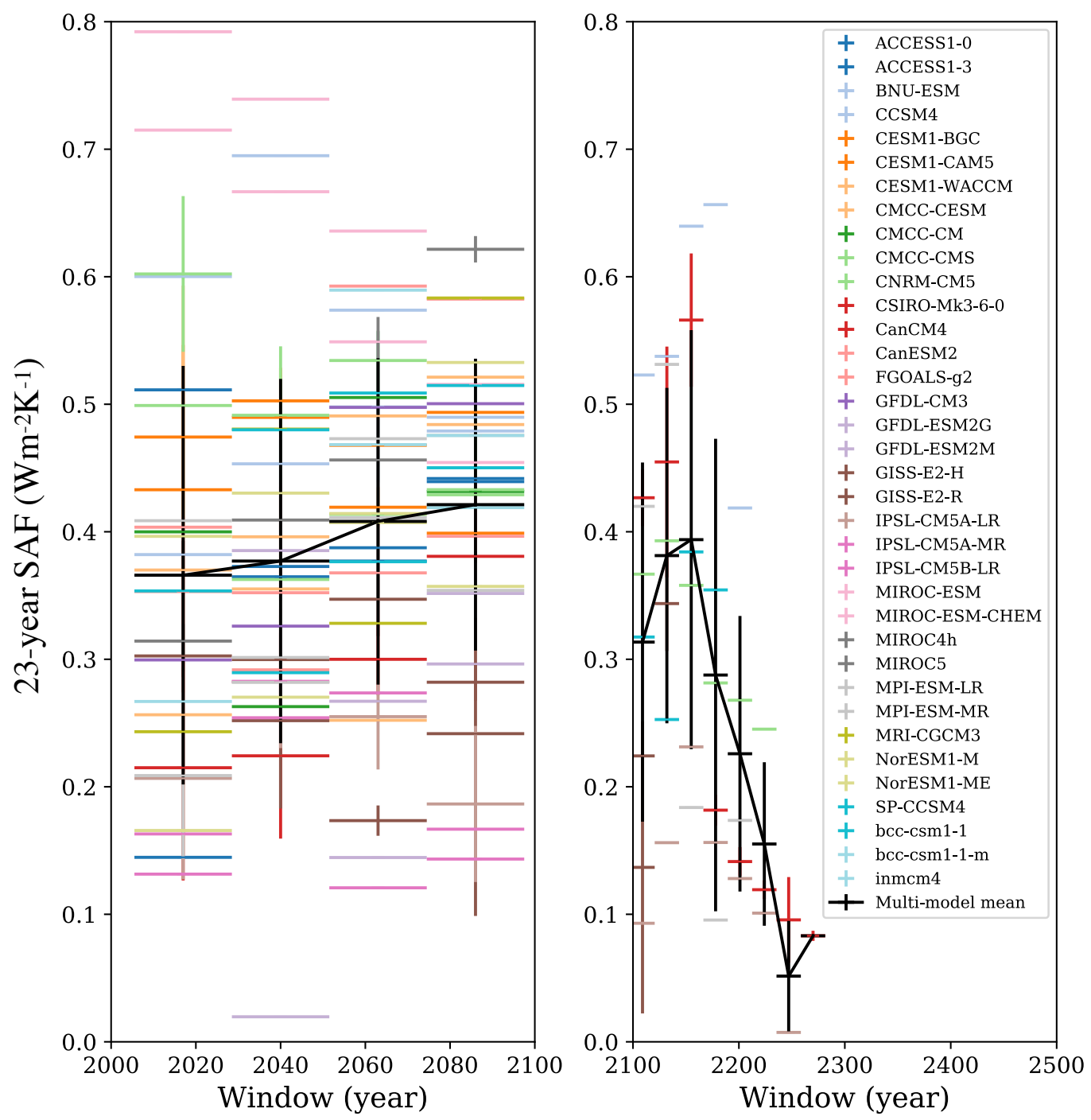

Figure 2. Temporal evolution of surface albedo feedback (SAF) in CMIP5 models calculated using the CESM1-CAM5 radiative kernel. Horizontal line segments mark 23-year ensemble mean SAFs in individual models (colors) calculated from multiple ensemble members. Black (connected) horizontal line segments mark multi-model mean 23-year SAF. Vertical error bars on individual model means represent ensemble member standard deviations. Black vertical error bars on multi-model means represent model standard deviations. Data displayed are calculated only from 23 -year periods with at least $0.5 \mathrm{~K}$ global mean surface temperature change. 

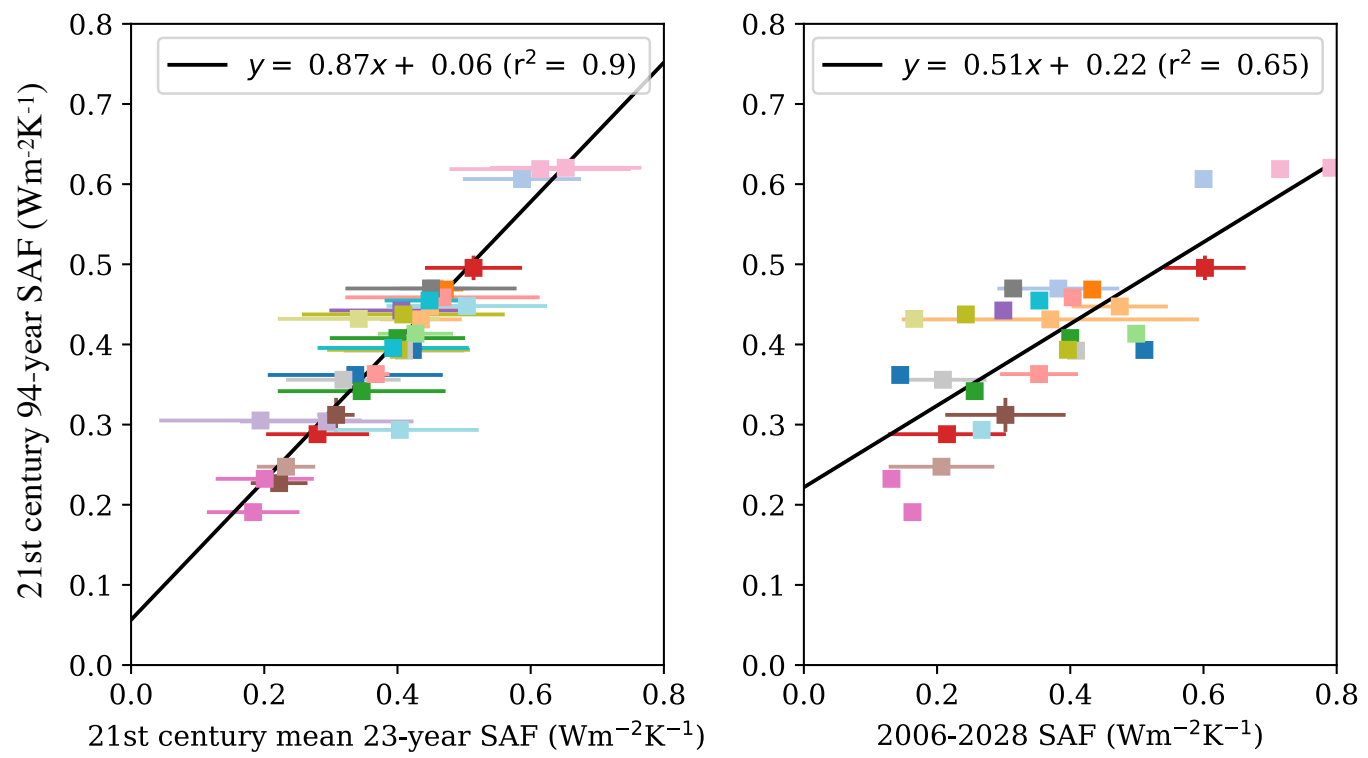

Figure 3. 21st century 94 -year model mean SAFs vs. 21st century 23-year model mean SAFs. Scattered data are displayed with their linear regressions plotted in black. On the left, 23-year model means are calculated from all four 23-year windows within the 21st century. Horizontal error bars represent standard error of ensemble member 23-year means. On the right, 23-year means are calculated from ensemble members with only the 2006-2028 period. Horizontal error bars represent ensemble member standard deviations. As in Figure 2, data displayed are calculated only from periods with at least $0.5 \mathrm{~K}$ global mean surface temperature change. Colors are assigned by model accordingly to the key in Figure 2.

year) SAF in Figure 3 (left). Encouragingly, model-mean 21st century 94-year SAF is strongly correlated $\left(r^{2}=0.90\right)$ with 21 st century model-mean 23 -year SAF. This strong correlation (standard error of regression $=0.05 \mathrm{Wm}^{-2} \mathrm{~K}^{-1}$ ) demonstrates that in general, 23-year SAF calculations are well representative of their century time-scale SAF. When we regress 23-year SAFs from only the first 23-year window (2006-2028) onto the 94-year SAFs (Figure 3, right), however, the correlation weakens $\left(r^{2}=0.65\right)$. The weaker correlation (standard error of regression $=0.07 \mathrm{Wm}^{-2} \mathrm{~K}^{-1}$ ) indicates that 23-year estimates of SAF from any one period are not strong predictors of century-scale SAF in transient climate. This finding is somewhat intuitive, as a single 23-year estimate of SAF cannot predict how SAF will evolve in a changing climate. Because 21st century mean 23-year SAF is strongly correlated with 21st century 94-year SAF, however, 23-year estimates of SAF can accurately quantify sub-century scale SAF as long as there is at least $0.5 \mathrm{~K}$ temperature change. This is useful for examination of the temporal variability within a longer timescale. These findings justify using 23 -year SAF to quantify time evolving decadalscale SAF, but using a temporally limited dataset to derive accurate estimates of long-term SAF in climate change is subject to considerable uncertainty.

With multiple decadal-scale SAF estimates in 21 st century climate simulations, we conclude that SAF does not decrease about its multi-model mean of $0.4(+/-0.1) \mathrm{Wm}^{-2} \mathrm{~K}^{-1}$ and possibly strengthens throughout the 21 st century. Of the 29 models with both early (2006-2028) and late (2075-2097) 21st century 23-year SAF in Table 1, 16 (55\%) show significant strengthening of SAF. With most CMIP5 models showing significant strengthening in SAF, multi-model mean SAF increasing, and a significant increase from the paired 
difference test, the CMIP5 multi-model ensemble results suggest SAF does not weaken in the 21st century. This finding is contrary to our initial expectations in simulations where diminishing Arctic sea-ice is common. Further investigation into the spatial distribution of the changing TOA net irradiance reveals more rapid Arctic albedo decline in late spring and early summer months toward the end of the 21 st century. Figure 4 gives a glimpse into this more rapid Arctic albedo decline in June, where we show the 23-year change in TOA net irradiance in the early versus late 21 st century in the CanESM2 and CESM1(WACCM) models. We select simulations from these two models because they have increasing 21st century SAF, relatively small 23-year standard deviations, and values similar to multimodel means in Table 1. In both simulations, June Arctic albedo decreases more rapidly in the late versus early 21 st century. The increasing Arctic albedo decline is typical among other models as well, suggesting that sea-ice decline is a key driver of persistent SAF strength throughout the 21st century. Increasing Antarctic albedo decline is also evident in Southern Hemisphere summer months.

\section{Conclusions}

This study examined decadal-scale variability of SAF using 36 climate models in the CMIP5 multi-model ensemble archive. After identifying asymptotic behavior in its calculation, we removed noisy SAF contributions by selecting only estimates from time periods exhibiting global mean temperature change of at least $0.5 \mathrm{~K}$ for analysis. This allowed for better interpretation of model and multi-model mean statistics from which we identified a relatively small but significant $(\mathrm{p}$-value $=0.04) 18 \%$ increase $(+/-16 \%$; $95 \%$ confidence interval) in SAF strength from 2017 to 2086 . We regressed century-scale against decadalscale SAF and verified that multiple shorter time-scale estimates are good predictors of their longer time-scale counterparts, while single 23-year estimates have limited utility. Finally, we investigated the spatial distribution of the changing TOA net irradiance and determined that late spring to early summer Arctic albedo declined more rapidly in late versus early 21 st century years in most models. We found evidence of dominant sea-ice contribution to persistent SAF strength late into 21 st century simulations.

The main implications of these findings follow. First, that decadal-scale SAF is correlated with century-scale SAF provides justification for using decadal-scale estimates to evaluate time-dependent variability of SAF. Extending SAF derived from remote sensing observations, (e.g., Flanner et al. [2011], Pistone et al. [2014], Cao et al. [2015]) that are limited in their temporal domain by the satellite era, onto longer time scales, however, is feasible but with limited accuracy. These results are of course restricted to time periods with sufficient climate change ( $>0.5 \mathrm{~K}$ ), and also predicated on model behavior exhibiting similar multi-decadal characteristics as the real climate system. Second, that CMIP5 multi-model ensemble mean SAF increases in the 21st century despite rapid seasonal snow and sea-ice cover loss demonstrates a persistent capacity for global surface albedo change extending through the end of the century. A closer look at the spatial distribution of albedo trends revealed a poleward shift in maximal albedo decline as well as late-spring to early summer prevalence in Arctic and Antarctic sea-ice melt.

\section{Acknowledgments}

This study is funded, in part, by the National Science Foundation, grant number ARC1253154.

We acknowledge the World Climate Research Programme's Working Group on Coupled Modelling, which is responsible for CMIP, and we thank the climate modeling groups (listed in Table 1 of this paper) for producing and making available their model output. For CMIP the U.S. Department of Energy's Program for Climate Model Diagnosis and Intercomparison provides coordinating support and led development of software infrastructure in partnership with the Global Organization for Earth System Science Portals. 
We wish to thank two anonymous reviewers for taking time to read the manuscript and for providing helpful comments.
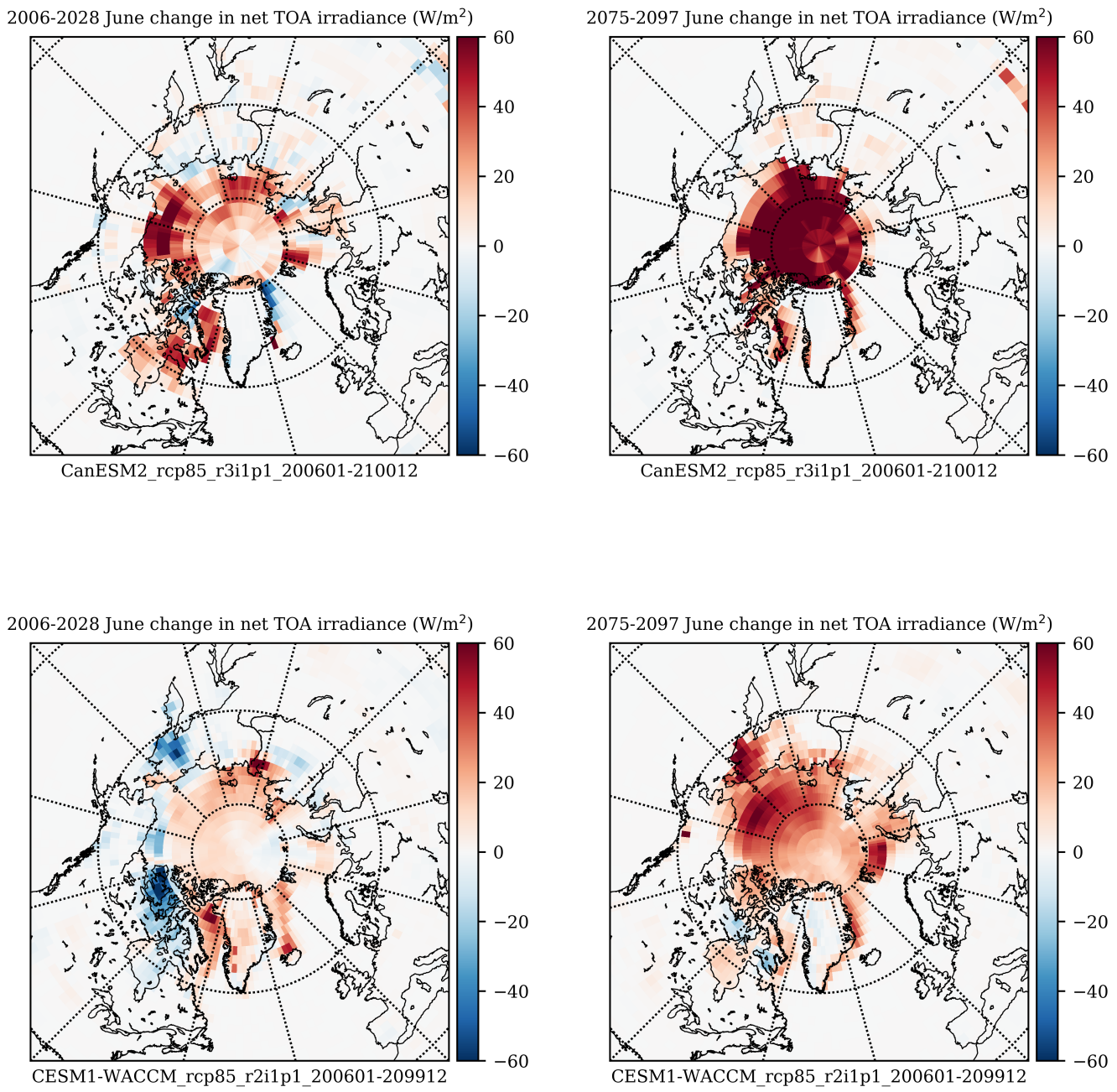

Figure 4. June 23-year change in net TOA irradiance caused by surface albedo changes in the early (left) versus late (right) 21st century. Filled contours map results from single ensemble member simulations in CanESM2 (top) and CESM1-WACCM (bottom) for northern latitudes (> 45 degrees N). Positive (red) values indicate increasing net TOA irradiance from decreasing surface albedo. 


\section{References}

Andry, O., R. Bintanja, and W. Hazeleger (2017), Time-Dependent Variations in the Arctic's Surface Albedo Feedback and the Link to Seasonality in Sea Ice, Journal of Climate, 30(1), 393-410, doi:10.1175/JCLI-D-15-0849.1.

Budyko, M. I. (1969), The effect of solar radiation variations on the climate of the Earth, Tellus, 21(5), 611-619, doi:10.1111/j.2153-3490.1969.tb00466.x.

Cao, Y., S. Liang, X. Chen, and T. He (2015), Assessment of Sea Ice Albedo Radiative Forcing and Feedback over the Northern Hemisphere from 1982 to 2009 Using Satellite and Reanalysis Data, Journal of Climate, 28(3), 1248-1259, doi:10.1175/JCLI-D-1400389.1.

Colman, R. A. (2013), Surface albedo feedbacks from climate variability and change: GCM ALBEDO FEEDBACKS, Journal of Geophysical Research: Atmospheres, 118(7), 2827-2834, doi:10.1002/jgrd.50230.

Crook, J. A., and P. M. Forster (2014), Comparison of surface albedo feedback in climate models and observations: Crook and Forster: Surface Albedo Feedback, Geophysical Research Letters, 41(5), 1717-1723, doi:10.1002/2014GL059280.

Fernandes, R., H. Zhao, X. Wang, J. Key, X. Qu, and A. Hall (2009), Controls on Northern Hemisphere snow albedo feedback quantified using satellite Earth observations, Geophysical Research Letters, 36(21), doi:10.1029/2009GL040057.

Flanner, M. G., K. M. Shell, M. Barlage, D. K. Perovich, and M. A. Tschudi (2011), Radiative forcing and albedo feedback from the Northern Hemisphere cryosphere between 1979 and 2008, Nature Geoscience, 4(3), 151-155, doi:10.1038/ngeo1062.

Flato, G., J. Marotzke, B. Abiodun, P. Braconnot, S. Chou, W. Collins, P. Cox, F. Driouech, S. Emori, V. Eyring, C. Forest, P. Gleckler, E. Guilyardi, C. Jakob, V. Kattsov, C. Reason, and M. Rummukainen (2014), Evaluation of Climate Models, in Climate Change 2013 - The Physical Science Basis, edited by Intergovernmental Panel on Climate Change, pp. 741-866, Cambridge University Press, Cambridge, dOI: 10.1017/CBO9781107415324.020.

Fletcher, C. G., H. Zhao, P. J. Kushner, and R. Fernandes (2012), Using models and satellite observations to evaluate the strength of snow albedo feedback, Journal of Geophysical Research, 117(D11), doi:10.1029/2012JD017724.

Fletcher, C. G., C. W. Thackeray, and T. M. Burgers (2015), Evaluating biases in simulated snow albedo feedback in two generations of climate models, Journal of Geophysical Research: Atmospheres, 120(1), 12-26, doi:10.1002/2014JD022546.

Hall, A. (2004), The Role of Surface Albedo Feedback in Climate, Journal of Climate, 17(7), 1550-1568, doi:10.1175/1520-0442(2004)017<1550:TROSAF>2.0.CO;2.

Hall, A., and X. Qu (2006), Using the current seasonal cycle to constrain snow albedo feedback in future climate change, Geophysical Research Letters, 33(3), doi: 10.1029/2005GL025127.

Hudson, S. R. (2011), Estimating the global radiative impact of the sea iceâĂŞalbedo feedback in the Arctic, Journal of Geophysical Research, 116(D16), doi: 10.1029/2011JD015804.

Intergovernmental Panel on Climate Change (Ed.) (2014), Climate Change 2013 - The Physical Science Basis: Working Group I Contribution to the Fifth Assessment Report of the Intergovernmental Panel on Climate Change, Cambridge University Press, Cambridge, dOI: 10.1017/CBO9781107415324.

Kay, J. E., B. R. Hillman, S. A. Klein, Y. Zhang, B. Medeiros, R. Pincus, A. Gettelman, B. Eaton, J. Boyle, R. Marchand, and T. P. Ackerman (2012), Exposing Global Cloud Biases in the Community Atmosphere Model (CAM) Using Satellite Observations and Their Corresponding Instrument Simulators, Journal of Climate, 25(15), 5190-5207, doi:10.1175/JCLI-D-11-00469.1.

Pistone, K., I. Eisenman, and V. Ramanathan (2014), Observational determination of albedo decrease caused by vanishing Arctic sea ice, Proceedings of the National 
Academy of Sciences, 111(9), 3322-3326, doi:10.1073/pnas.1318201111.

Pithan, F., and T. Mauritsen (2014), Arctic amplification dominated by temperature feedbacks in contemporary climate models, Nature Geoscience, 7(3), 181-184, doi: 10.1038/ngeo2071.

Qu, X., and A. Hall (2006), Assessing Snow Albedo Feedback in Simulated Climate Change, Journal of Climate, 19(11), 2617-2630, doi:10.1175/JCLI3750.1.

Qu, X., and A. Hall (2007), What Controls the Strength of Snow-Albedo Feedback?, Journal of Climate, 20(15), 3971-3981, doi:10.1175/JCLI4186.1.

Qu, X., and A. Hall (2014), On the persistent spread in snow-albedo feedback, Climate Dynamics, 42(1-2), 69-81, doi:10.1007/s00382-013-1774-0.

Roberts, J., and T. D. Roberts (1978), Use of the Butterworth low-pass filter for oceanographic data, Journal of Geophysical Research, 83(C11), 5510, doi: 10.1029/JC083iC11p05510.

Sellers, W. D. (1969), A Global Climatic Model Based on the Energy Balance of the Earth-Atmosphere System, Journal of Applied Meteorology, 8(3), 392-400, doi: 10.1175/1520-0450(1969)008<0392:AGCMBO>2.0.CO;2.

Shell, K. M., J. T. Kiehl, and C. A. Shields (2008), Using the Radiative Kernel Technique to Calculate Climate Feedbacks in NCARâĂŹs Community Atmospheric Model, Journal of Climate, 21(10), 2269-2282, doi:10.1175/2007JCLI2044.1.

Soden, B. J., and I. M. Held (2006), An Assessment of Climate Feedbacks in Coupled Ocean Atmosphere Models, Journal of Climate, 19(14), 3354-3360, doi: 10.1175/JCLI3799.1.

Soden, B. J., I. M. Held, R. Colman, K. M. Shell, J. T. Kiehl, and C. A. Shields (2008), Quantifying Climate Feedbacks Using Radiative Kernels, Journal of Climate, 21(14), 3504-3520, doi:10.1175/2007JCLI2110.1.

Taylor, K. E., R. J. Stouffer, and G. A. Meehl (2012), An Overview of CMIP5 and the Experiment Design, Bulletin of the American Meteorological Society, 93(4), 485-498, doi:10.1175/BAMS-D-11-00094.1.

Vial, J., J.-L. Dufresne, and S. Bony (2013), On the interpretation of inter-model spread in CMIP5 climate sensitivity estimates, Climate Dynamics, 41(11-12), 3339-3362, doi: 10.1007/s00382-013-1725-9.

Winton, M. (2006a), Amplified Arctic climate change: What does surface albedo feedback have to do with it?, Geophysical Research Letters, 33(3), doi:10.1029/2005GL025244.

Winton, M. (2006b), Surface Albedo Feedback Estimates for the AR4 Climate Models, Journal of Climate, 19(3), 359-365, doi:10.1175/JCLI3624.1. 


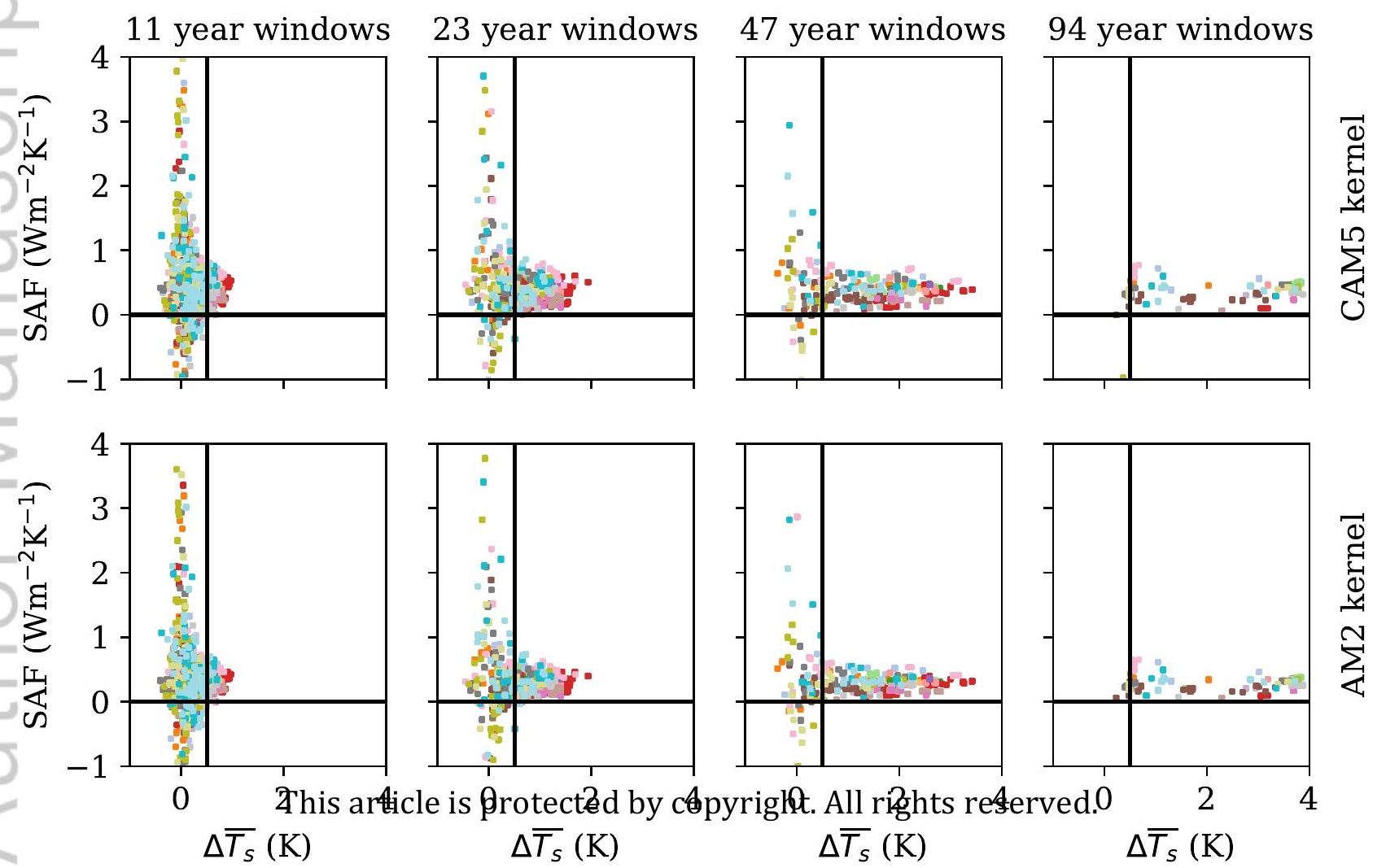


Figure 2.
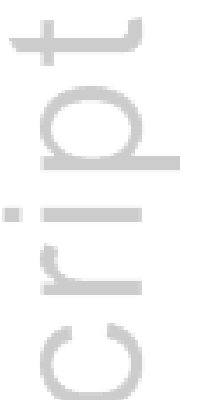

$\infty$
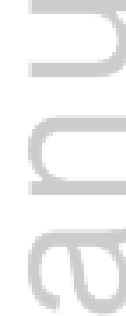

This article is protected by copyright. All rights reserved. 



This article is protected by copyright. All rights reserved. 


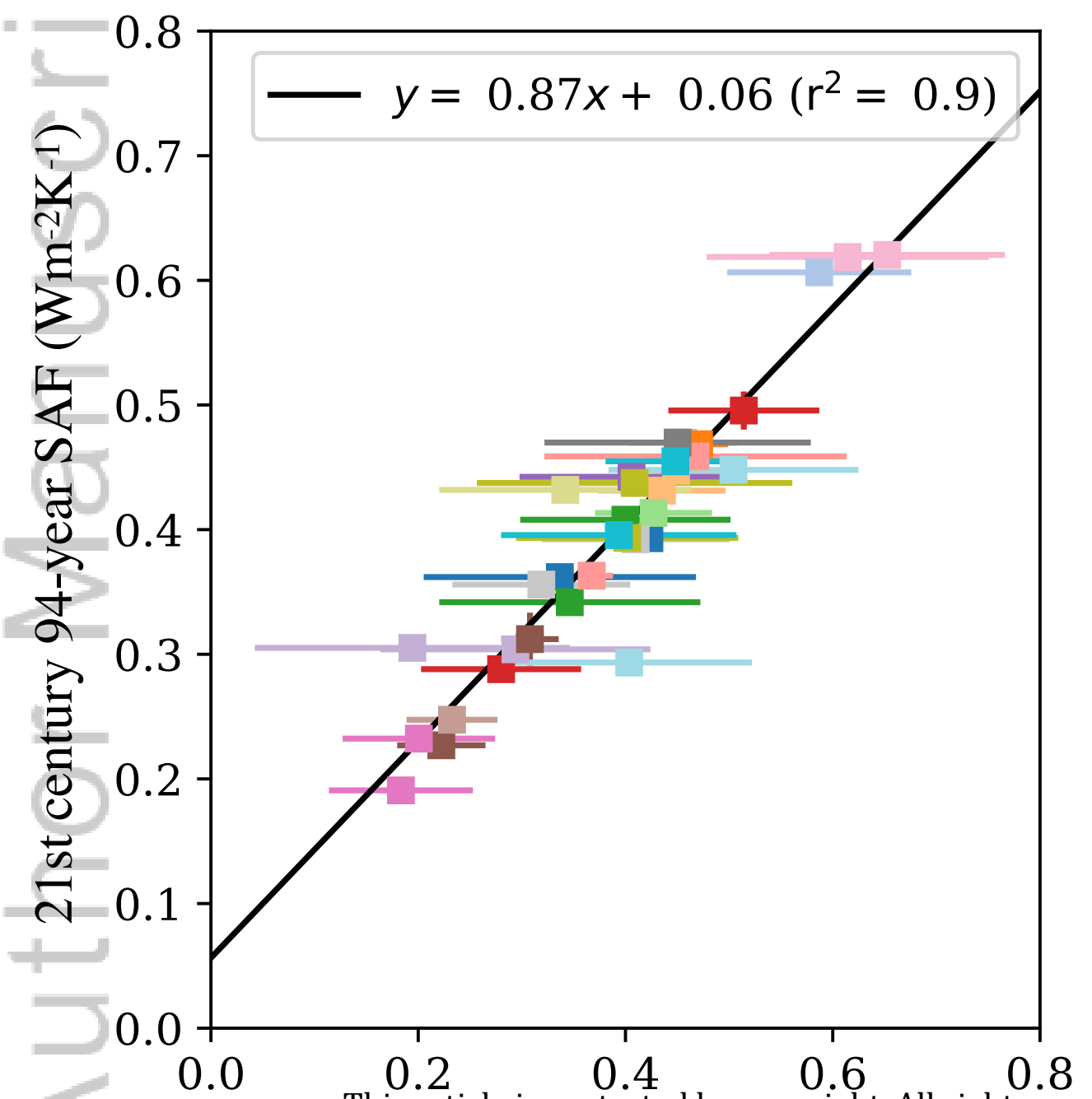

$0.0 \quad$ This article is protected by copyright. All rights reserved. 21st century mean 23-year SAF (Wm $\left.{ }^{-2} \mathrm{~K}^{-1}\right)$

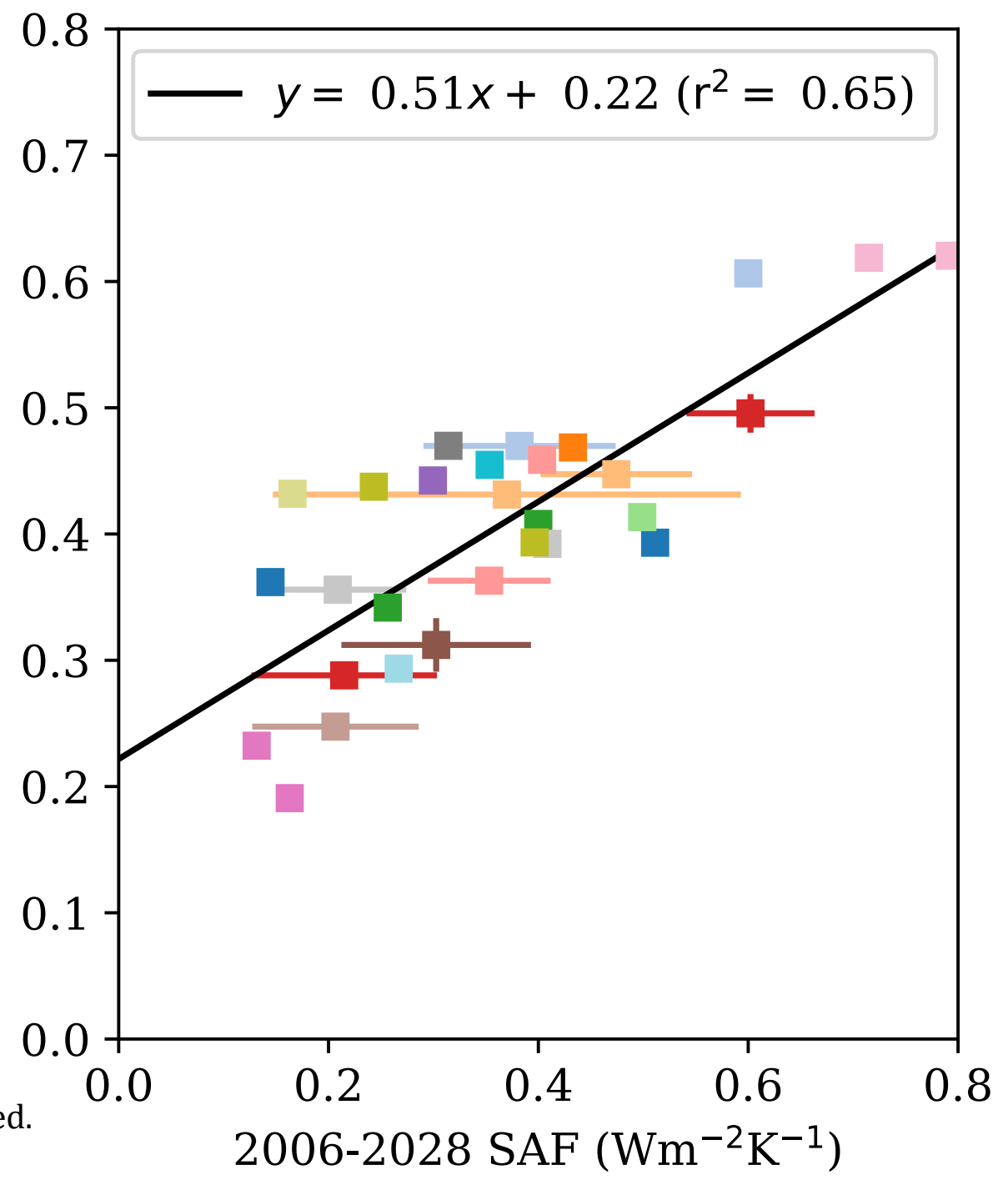


2006-2028 June change in net TOA irradiance $\left(\mathrm{W} / \mathrm{m}^{2}\right)$

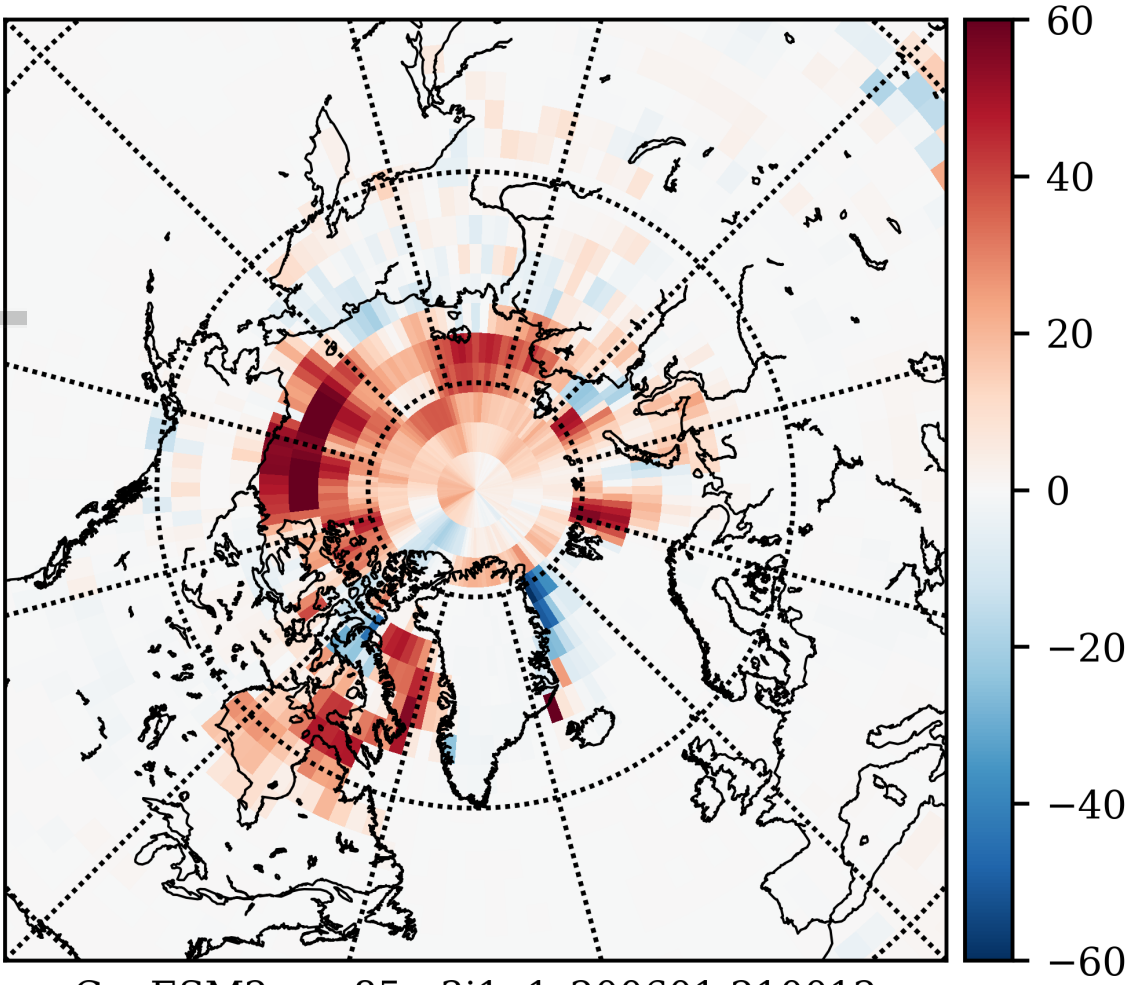

CanESM2_rcp85_r3i1p1_200601-210012
2075-2097 June change in net TOA irradiance $\left(\mathrm{W} / \mathrm{m}^{2}\right)$

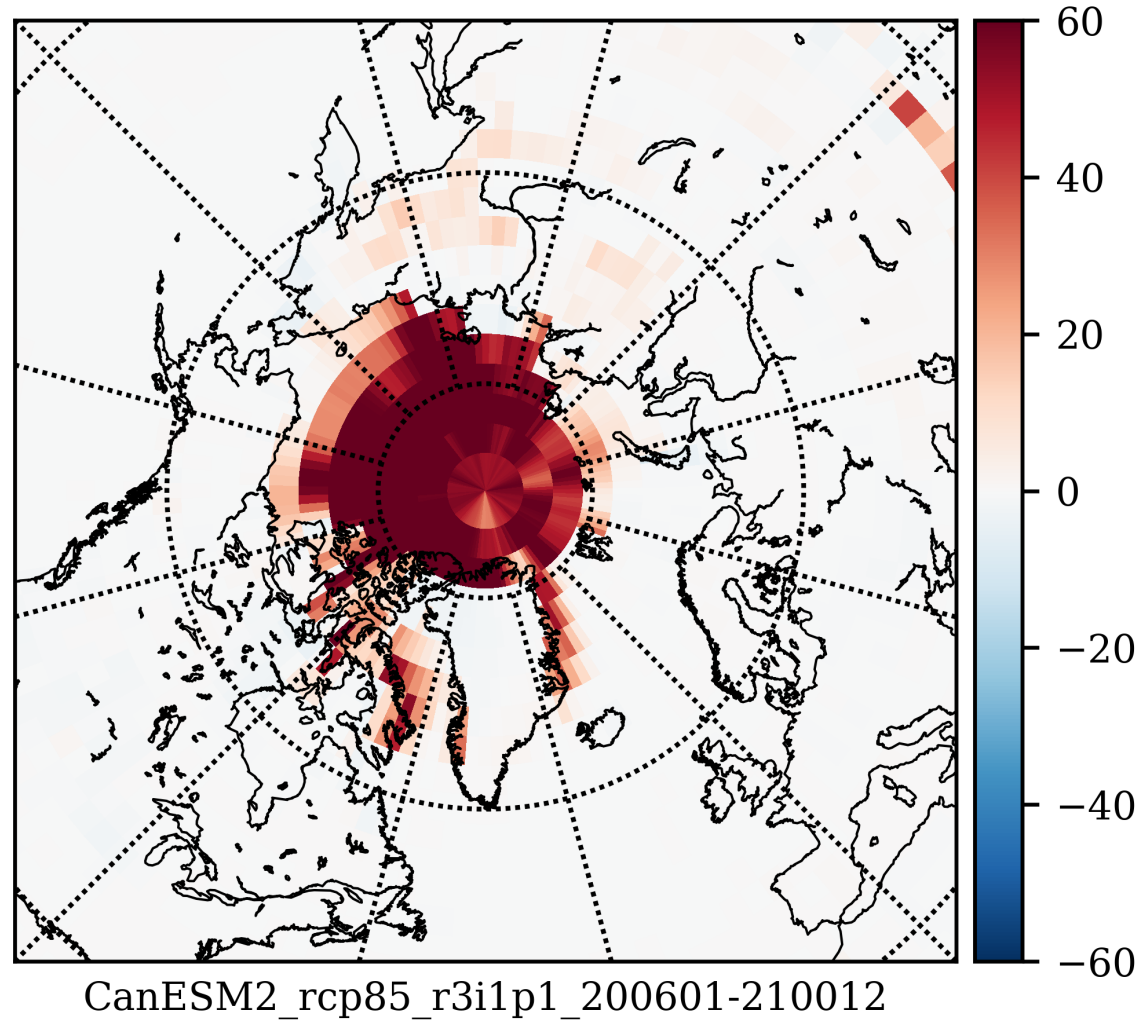

2006-2028 June change in net TOA irradiance $\left(\mathrm{W} / \mathrm{m}^{2}\right)$

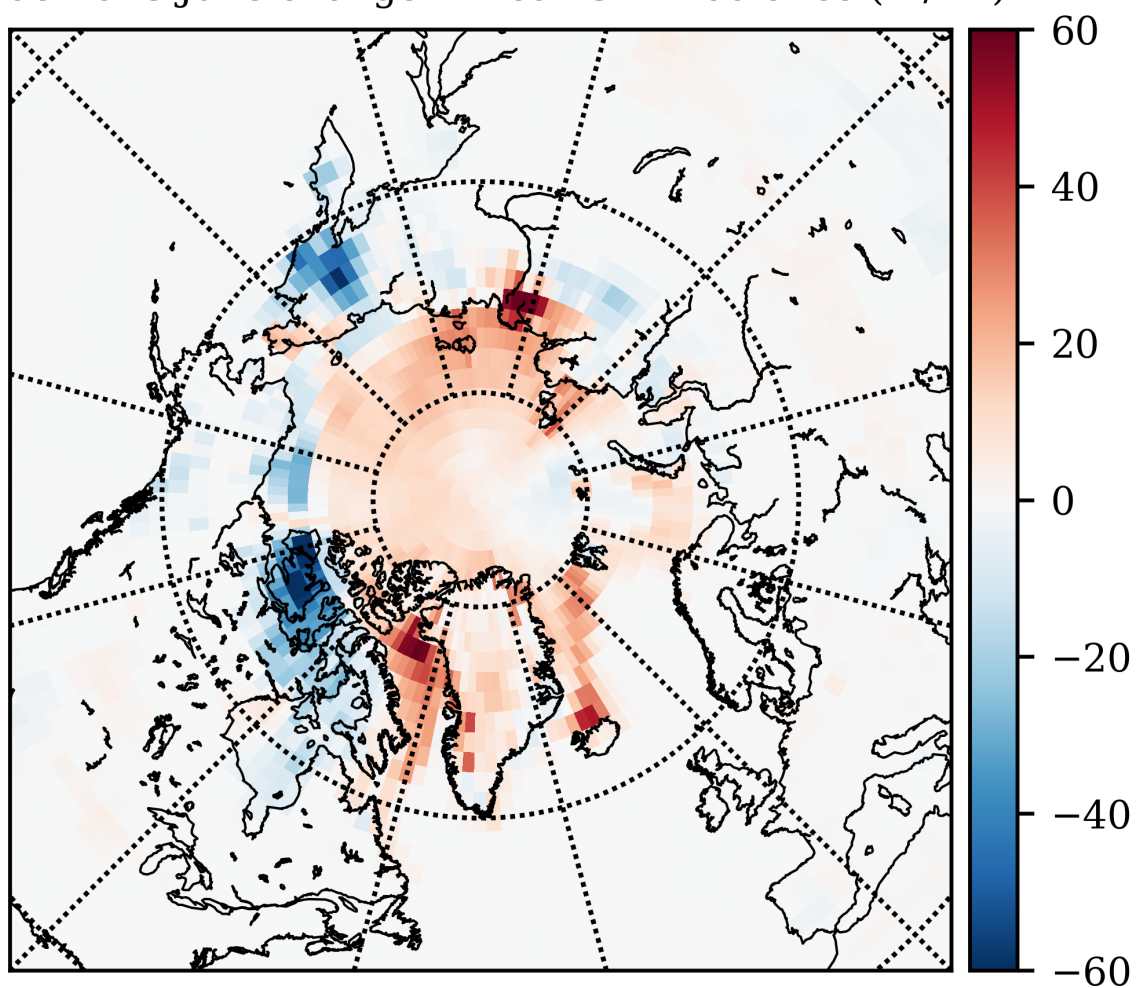

CESM1-WACCM_rcp85_r2i1p1_200601-209912
2075-2097 June change in net TOA irradiance $\left(\mathrm{W} / \mathrm{m}^{2}\right)$

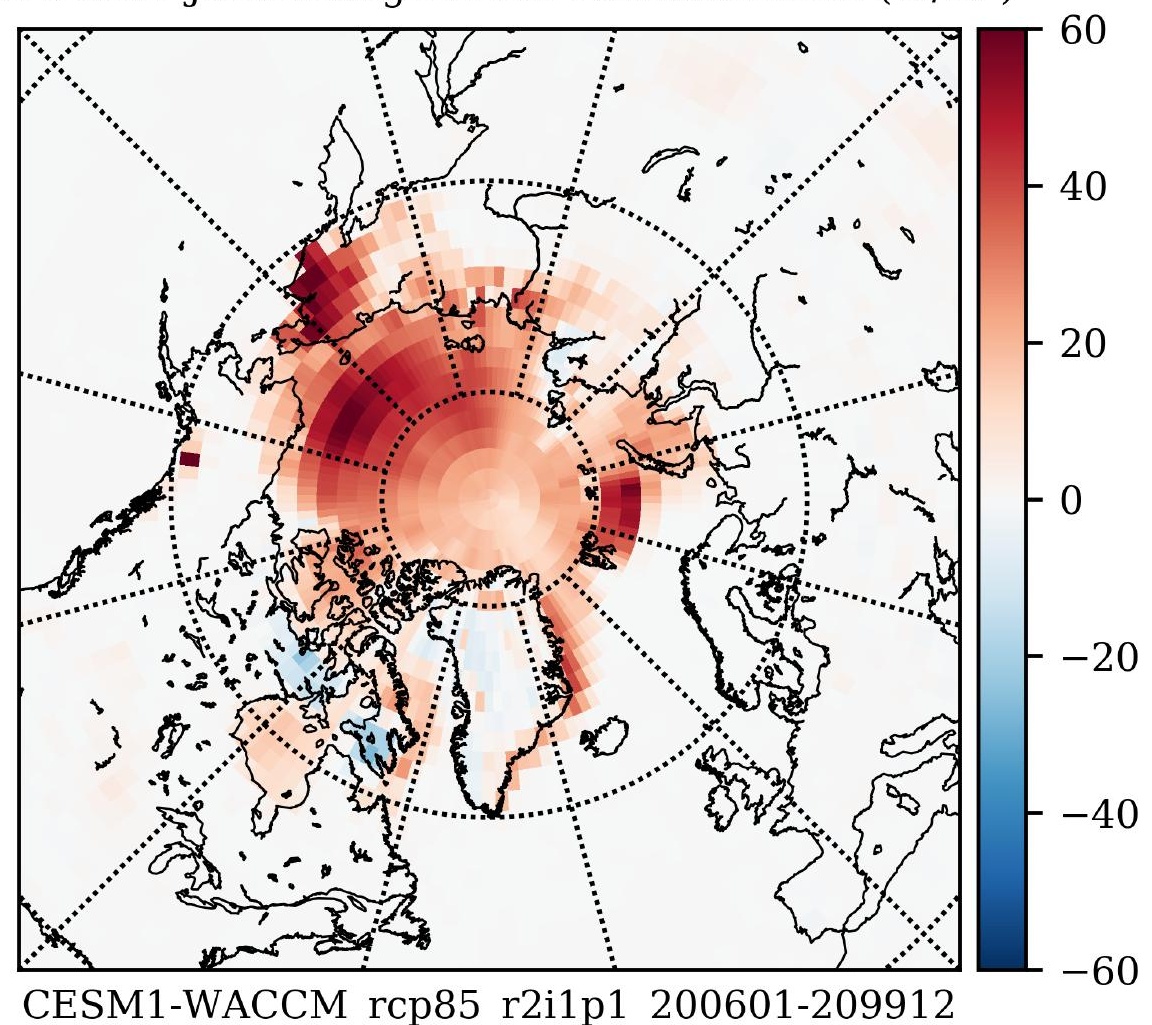

CESM1-WACCM_rcp85_r2i1p1_200601-209912 